Session 3548

\title{
The Ekranoplan Vehicle Design Project
}

\author{
Eric Leonhardt \\ Western Washington University
}

\begin{abstract}
The Ekranoplan project offers technology educators an additional inexpensive and creative design project that is appropriate for students from middle school through university. The project excites students about technology while motivating them to learn math and science using a team-oriented environment. The project utilizes learning objectives that may be tied to standardized assessments.

Masters of Education candidates at Western Washington University developed the Ekranoplan vehicle project during a Technology Education course. An Ekranoplan or Wing-In-Ground Effect vehicle flies very close to a water surface. The vehicle uses design elements of both airplanes and marine craft. Ground-effect flight enables a vehicle to carry either a larger payload or operate with greater fuel efficiency than a conventional airplane. The candidates tested several vehicle configurations, power sources and construction techniques. Vehicle construction guidelines and curriculum outlines were developed to disseminate to other technology educators. The project has been used to teach the engineering design process to freshman students in Western Washington University's Engineering Technology Design Graphics course.
\end{abstract}

\section{Introduction}

Masters of Education candidates within the Technology Education program are required to develop vehicle-based technology projects to use in their own high school and middle school classes. The purpose of the vehicle project is to motivate students to learn about teamwork, engineering design, math, physics and technology. The candidates create a curriculum plan that incorporates the project. The curriculum plan includes the educational objectives that the candidates intend to meet and the assessment tools that the candidates will use. The candidates build examples of the vehicles and test them in a friendly competition at the end of the course. During the summer of 2002, candidates were introduced to the Ekranoplan vehicle. This vehicle provides educators with an interesting and creative project for all levels of technology education.

\section{What is an Ekranoplan?}

Ekranoplan is a Russian word for a vehicle that exploits the benefits of ground effect flight. The Ekranoplan or Wing-In-Ground Effect vehicle flies in close proximity to a surface, usually water, to improve the lift to drag ratio of its airfoils. The improvement in the lift to drag ratio enables either the size of the wing to be reduced or larger cargo capacity. For a given vehicle and payload, reducing the size of the wing may improve fuel economy by reducing a vehicle's drag. ${ }^{1}$ The ground effect benefit improves as vehicle size grows. Some of the largest flying

"Proceedings of the 2004 American Society for Engineering Education Annual Conference \& Exposition Copyright $(02004$, American Society for Engineering Education” 
machines utilize ground-effect flight. The Alexeiev Central Hydrofoil Design Bureau built many vehicles in the former Soviet Union. ${ }^{2}$ The largest of these, the KM, reached a gross weight of 540 tons -90 tons more than a Boeing 747 Jumbo Jet.

As a vehicle project, the Ekranoplan's capability matches the unique marine environment found near Western Washington University. As an educational project, the Ekranoplan provides students with an opportunity for, in the words of Jean Piaget, "active discovery of reality."3

Several of the candidates in the summer of 2002 class had already used technology projects in their classrooms. These experienced technology educators demanded a new project to spark the interest of their students. The author challenged the candidates to develop a project around the Ekranoplan vehicle technology. Initially the candidates were not aware of these obscure vehicles. The candidates began by reviewing information available on the Internet. Few books have been written about these vehicles and some of the books are only available in Russian or German. The candidates were able to look at a plastic, Revell ${ }^{\circledR}$ model of the nearly 58 meter long, Russian A-90 Orljonok Ekranoplan. In addition to books and web pages, the candidates found a History Channel ${ }^{\circledR}$ program that described the accomplishments of Russian engineer Rostilav Alexeiev, a pioneer of ground effect flight. ${ }^{4}$

\section{Lessons in Aerodynamics}

The project provides students the opportunity to learn about lift, drag, thrust and ground effect flight. Vocabulary words, such as wingspan, chord, aspect ratio and plan area, are discussed. Concepts presented to university students include angle of attack, stall, Reynolds number and pitching moment. Lift is introduced as the force that allows the plane to fly. Two methods are used to describe this force, one based upon Bernoulli and one based upon Newton. According to the Bernoulli explanation, lift occurs because air moving more rapidly over the top airfoil surface reduces the pressure above a wing. The pressure differential between the top and bottom wing surfaces generates a lifting force. The effect may be demonstrated by holding a piece of notebook paper along one edge and blowing across the drooping paper. The Newtonian approach explains that as air travels across the highly curved upper surface of an airfoil, the viscous nature of air allows the air to follow the curvature. As a result, the air changes direction and is deflected downward after leaving the wing. Since every action has an equal and opposite reaction, the mass of air directed downward generates a corresponding lift in the vehicle. This approach is also known as the change in momentum approach. Both explanations can be used to accurately describe lift.

Students learn to calculate the lift associated with a particular airfoil based upon a lift coefficient and the following formula:

$$
\text { Lift }=\text { Coefficient of Lift } *\left(1 / 2 \text { Mass Air Density*Velocity }{ }^{\wedge}\right) * \text { Wing Plan Area }{ }^{5}
$$

The lift coefficient may be found in the Theory of Wing Sections ${ }^{6}$ or on an Internet site that offers airfoil data. Lift coefficients are given in terms of an airfoil's angle of attack and its Reynolds number. The angle of attack refers to an angle between the chord, or distance between the nose and trailing edge of an airfoil, and a horizontal line. Aerodynamic vehicles of a similar form and yet different size may be compared as long as their Reynolds number is similar. Model 
vehicles and their full size counterparts may be compared if they are tested and operated at the same Reynolds number. The Reynolds number relates the length of a body, the speed at which a fluid travels relative to the body, and the fluid's kinematic fluid viscosity (viscosity divided by density). The Reynolds number characterizes when flow around a body is turbulent or laminar. As an aerodynamic body becomes smaller, either the relative velocity of the testing fluid increases or the kinematic viscosity must decrease. For builders of model Ekranoplan vehicles, the lift and drag data for wing profiles are generally given for Reynolds numbers significantly above those required by small model vehicles. Students may calculate the appropriate data for a full-scale version of their design, or they may estimate the model vehicle's performance by extrapolating from the wing section data.

Students perform similar calculations for drag, or the resistance to vehicle's forward motion. Attempts to measure the thrust, or propeller force, have not yet been successful for the rubber band propelled craft. Various Newton force meters have been tested. Even with modified springs, the meters tested to date have been too stiff.

During flight, a pressure differential forms between the upper and lower surfaces of an airplane wing. Air will travel from the relatively high-pressure region below the wing to the lower pressure area above the wing. This movement occurs at the wingtips and causes wingtip vortices to form. The vortices create a type of drag known as induced drag. A similar phenomenon may be observed while following automobiles on a rainy day at freeway speeds. Ekranoplan or Wing-In-Ground Effect vehicles fly close enough to the ground that the ground prevents the formation of the tip vortices. The reduction in induced drag leads to an improvement in a wing's lift to drag ratio. The effect is strongly dependent upon the distance between the ground and the airfoil. The effect is non-linear. At an altitude equal to one wingspan, the effect is negligible, but at an altitude equal to one tenth of a wingspan, the induced drag may drop to $40 \%$ of the normal induced drag. ${ }^{7}$

\section{Vehicle Design and Construction}

The master's candidates were challenged to determine the types of construction techniques, airfoil configurations, and power plants suitable for a middle or high school student project. Without clear directions or plans, a process of trial and error led the design process. Fortunately, one candidate completed a vehicle at night following the first day of class. Using rubber-band power, the vehicle flew a few feet during the second day of class. This early success motivated the other candidates to complete their own vehicles. Each day the test flights achieved greater distances.

Balsa wood, tissue paper, foam and glue formed the structures of most of the vehicles. The candidates found that model aircraft hobby stores sell a special, low-density tissue paper. One candidate used a more commonly available tissue paper and then doped the tissue with a mixture of half water and half Elmer's ${ }^{\circledR}$ white glue. The diluted glue mixture tightened the tissue over the wing ribs to provide a more effective airfoil shape. Another candidate used ordinary typing paper for wing skins. This approach led to a significantly heavier vehicle that did not fly. A plastic film called Monokote ${ }^{\circledR}$ replaced tissue paper on one vehicle. Monokote ${ }^{\circledR}$ or a similar product is preferred by builders of radio controlled, model aircraft.

"Proceedings of the 2004 American Society for Engineering Education Annual Conference \& Exposition Copyright $(2004$, American Society for Engineering Education” 
The candidates designed their wings based upon airfoil profiles found on the Internet or in Theory of Wing Sections. ${ }^{8}$ The University of Illinois at Urbana-Champaign provides an extensive database of airfoil profiles. The dimensionless profiles provide two-dimensional $\mathrm{X}$ and $\mathrm{Y}$ coordinates for a cross section of an airfoil. The airfoil coordinates are provided in terms of the chord length. The chord length is zero at the nose of the wing and extends to " 1 " at the trailing edge. The Y coordinate varies as a function of the chord to create the shape of the upper and lower wing surfaces. The candidates attempted a variety of methods to convert the airfoil profiles into usable wing ribs. Some airfoil profiles could be printed directly and scaled to the desired size using a copy machine. In several cases the profiles were imported to a Computer Aided Design package such as AutoCAD ${ }^{\circledR}$ or Rhinoceros ${ }^{\circledR}$ and then manipulated using the CAD package. One candidate used both the data exchange format, DXF and the International Graphical Exchange format IGES to transfer the data into a Computer Aided Manufacturing package called SmartCam ${ }^{\circledR}$. This package allowed wing profile templates to be cut from wood using a 3-axis, computer numerically controlled router called a ShopBot ${ }^{\circledR}$. Both the paper profile patterns and the wood patterns guided a hot wire cutter to produce polystyrene foam wing ribs from building insulation. The rib ranged in thickness from $25 \mathrm{~mm}$ to around $6 \mathrm{~mm}$ (1" to 1/4"). The thinner rib allowed for lighter overall wing designs. The ribs were joined with balsa spars of various sizes from $3 \mathrm{~mm}(1 / 8$ ") square up to around $6 \mathrm{~mm}(1 / 4$ ") square.

The candidates found success with a wide variety of vehicle configurations. Most of the vehicles used a large main wing in front of a smaller horizontal wing for pitch stability. A single balsa wood fuselage connected the wings and provided a location to mount the rubber band, propeller and vertical tail surface. One vehicle used a tandem wing configuration while other vehicles used a reversed delta wing with negative dihedral along the leading edge - a design championed by aeronautical engineer Alexander Lippisch.

All of the wing configurations with flat or nearly flat bottom airfoil shapes flew. Only the prototype with a pronounced Lippisch style wing did not fly. All of the vehicles used wingspans of between $30 \mathrm{~cm}$ and $60 \mathrm{~cm}$ with chords no larger than $30 \mathrm{~cm}$. These small craft are sensitive to altitude, main airfoil pitch and the shape of the bottom of the wing. At this scale, a large part of the Lippisch style wing was more than $25 \mathrm{~mm}$ from the ground at rest. Most of these vehicles flew at altitudes of $12 \mathrm{~mm}$ to $50 \mathrm{~mm}$ with flat bottoms. It seems that the more pronounced Lippisch style wing could not generate enough pressure from the bottom of the wing to support ground effect flight. An example of the first Lippisch style prototype with its early paper covering is pictured in Figure 1 and Figure 2.

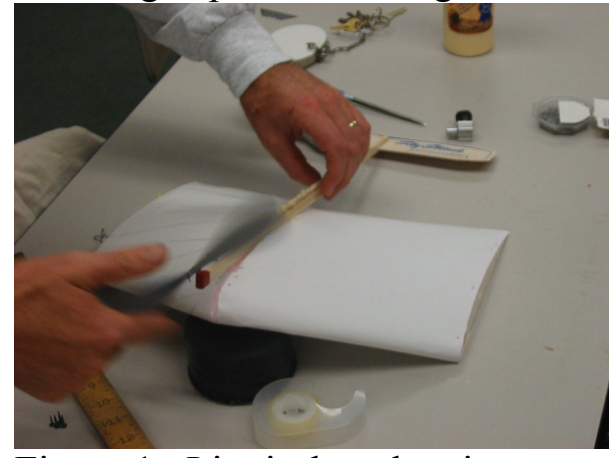

Figure 1. Lippisch style wing

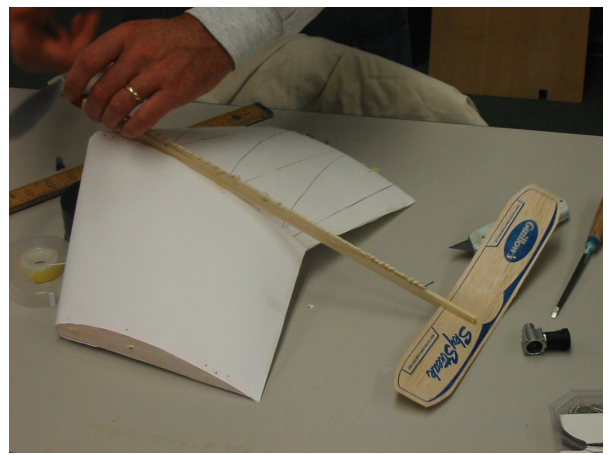

Figure 2. Early paper covering adds mass

"Proceedings of the 2004 American Society for Engineering Education Annual Conference \& Exposition Copyright $(02004$, American Society for Engineering Education” 
Two or three rubber bands of $150 \mathrm{~mm}$ long (relaxed) with a $1.5 \mathrm{~mm}$ by $3 \mathrm{~mm}$ cross section powered many of the craft. Figure 3 displays a sketch of a typical design. The candidates found plastic propellers of $150 \mathrm{~mm}$ diameter that were larger than those found in $\$ 3$ or less balsa wood airplane kits. One candidate brought a supply of two-stroke, $0.049 \mathrm{cc}$ displacement model aircraft engines to power the tandem wing prototype. The tandem wing craft is pictured in Figure 4. A compressed air reciprocating piston motor was borrowed from a child's toy to power another prototype. The compressed air motor provided high power with less noise than the two-stroke engine. Several electric motors were tested, but none of them were powerful enough to overcome the weight of their own batteries.

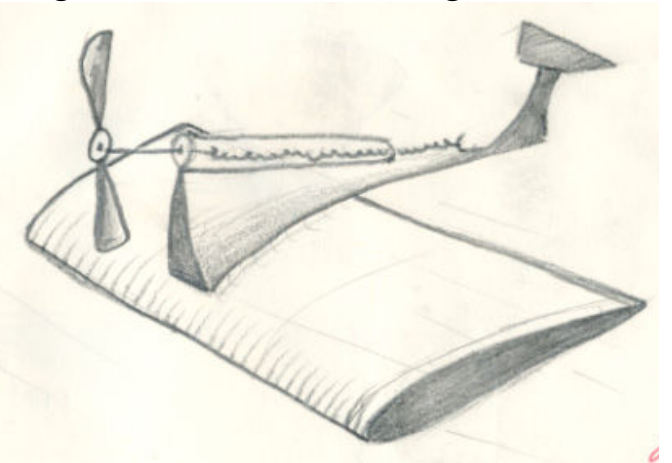

Figure 3. Typical vehicle design

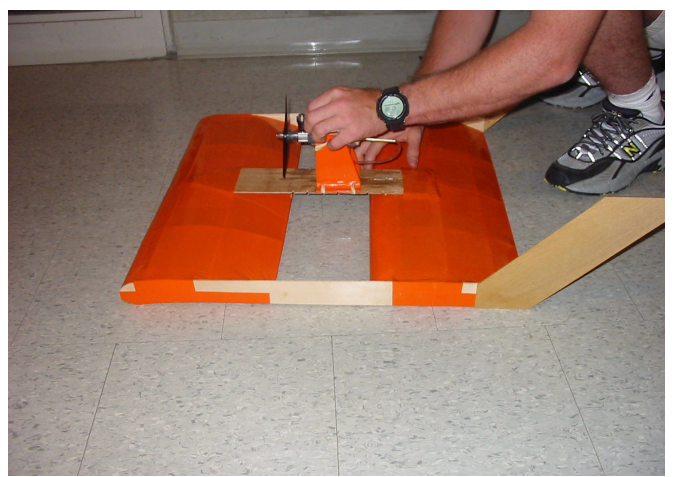

Figure 4. Two-stroke powered tandem wing

\section{Testing and Learning}

During the course the candidates attempted numerous flights with their prototypes down empty hallways. The tests allowed the candidates to test their design theories and adjust the flight dynamics of the vehicles. The wing loading was the largest factor determining whether or not a vehicle could fly. Wing loading is the weight of the vehicle divided by the plan area of the wing, as viewed from above. The rubber band powered vehicles flew with wing loadings of $7.5 \mathrm{~N} / \mathrm{m}^{2}$ $\left(0.156 \mathrm{lb} / \mathrm{ft}^{2}\right)$ or less. The candidates observed how the torque of the propeller caused the vehicles to turn. Another vehicle behavior was more difficult to explain. As the vehicles approached the end of their flights, they rotated (pitched) up and flew briefly out of ground effect. After several tests it was determined that the slowing propeller created drag. Since the propeller was mounted above the center of gravity, the slowing propeller created an upward pitching moment. The candidates enjoyed discussing each flight behavior. Evidence of their enthusiasm might be found in the number of modifications and prototypes produced. Eight candidates produced eleven vehicles. The vehicles that survived until the final gymnasium test day are pictured in Figure 4.

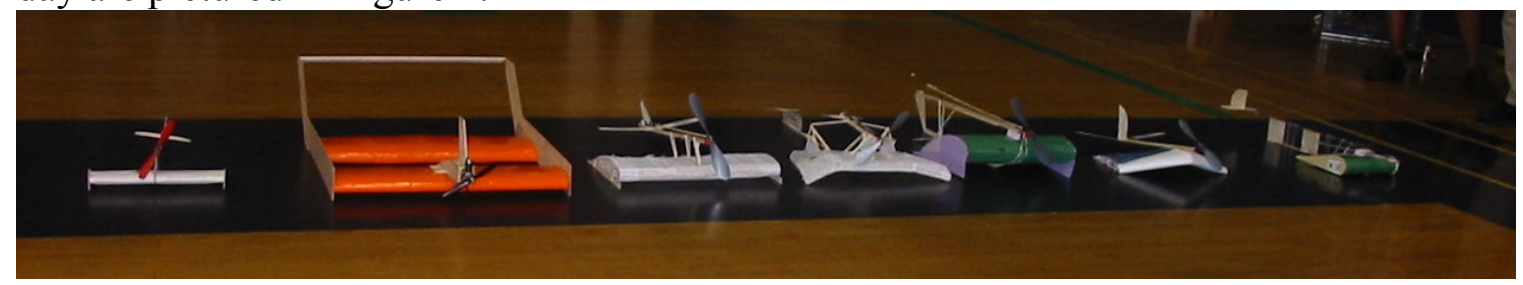

Figure 4. Ekranoplan vehicles compete for longest flight honors

Four of the vehicles achieved flights of more than fifteen meters. The tandem wing, two-stroke engine powered vehicle flew over 34 meters before striking the end of the gymnasium. One of 
the rubber band powered vehicles traveled 34 meters before reaching a wall. The air piston powered vehicle did not make the final test. It is anticipated that this vehicle could have traveled 34 meters.

\section{Answering Challenges Facing Technology Educators}

The candidates wanted to demonstrate the value of technology education to their schools by developing projects that would support the state assessment guidelines, with minimal costs. Using the Ekranoplan project as a base, these technology educators developed an answer for one of their major challenges: Washington Assessment of Student Learning. The Washington Assessment of Student Learning guidelines provide educators with Essential Learning Requirements for students at all grade levels. These guidelines cover a wide variety of areas including analytical skills, mathematical skills, and skills in the physical sciences. Critical thinking and writing skills are also required. Current guidelines for standardized testing in Washington State do not have a formal role for technology education. As result, school districts do not support programs that are not clearly defined and measured by the standardized assessment tools.

The candidates created curriculum outlines with learning objectives linked to the Essential Learning Requirements. In addition, the candidates looked at the Standards for Technology Literacy 9 . The candidates discussed how the Technology Content Standards could be incorporated into the Ekranoplan design project. One of the candidates linked the Technology Content Standards into a proposed project curriculum. ${ }^{10}$ Table 1 lists these standards.

Table 1. Technology Content Standards

\begin{tabular}{|c|l|}
\hline Standard Number & Technology Content Standard \\
\hline 8 & The attributes of design. \\
\hline 9 & Engineering design. \\
\hline 10 & $\begin{array}{l}\text { The role of troubleshooting, research and development, invention and } \\
\text { innovation, and experimentation in problem solving. }\end{array}$ \\
\hline 11 & Apply the design process. \\
\hline 12 & Use and maintain technological products and systems. \\
\hline
\end{tabular}

Most of the candidates created curriculum outlines that included a research component, a design and build component, and a competition component. ${ }^{11}$ The outlines proposed project durations of one to three weeks. Each candidate created a unique design problem for students to solve using the Ekranoplan technology. One candidate proposed that students create a new transportation system for the Marshall Islands. ${ }^{12}$ Half of the candidates specified a group project with two to four students. One candidate proposed an individual project. Several of the projects required students to keep a design journal to document their research, design concepts, and final results. The candidates debated how specific their competition rules for their students should be. Six of the candidates created competition rules based on rubber band powered vehicles. Vehicle size limitations were provided in a few cases. All of the candidates used the project to introduce concepts from mathematics, physics and technology. Specific concepts introduced by the project included vehicle mass, thrust, aerodynamic lift and drag, torque, relationships between thrust and lift, materials ${ }^{13}$, and structures. 


\section{Adapting the Ekranoplan Project to a Freshman Design Course}

The enthusiasm and excitement of the master's candidates encouraged two faculty members to adopt the Ekranoplan project as a team project in their Winter 2003 sections of Engineering Design Graphics I. This entry-level course introduces Engineering Technology college students to the design process, computer-aided design tools, and sketching. The eight-week course is split into a computer-aided design lab component, a sketching lab, and a weekly lunch lecture. Students work on three projects to help them integrate and develop their engineering process skills, creativity, sketching ability, and computer-aided design capability. The first and last projects are individual projects while the middle project relies on teams of two to four students. The Ekranoplan project targeted several educational objectives in Engineering Design Graphics I. Students could participate in a more complete engineering design process. Using the Ekranoplan project, students should develop a stronger understanding of the engineering design process to help them with their own personal goals and career development. ${ }^{14}$ The project should challenge student's creativity, design skills, and their developing computer aided design skills. Students should work through the process of building a physical prototype while overcoming limitations in materials, their own skill level, and the software/CAD capability. The project offered a potential link between vehicle design objectives, engineering specifications, and physical prototype performance.

The Ekranoplan project provided a benefit by linking the student's initial design objectives with a prototype development phase. Prior to the Ekranoplan project, the team project required that students conceptualize, sketch and design a product. The students were not required to create a prototype of the product. Students were also required to stretch their computer-aided design skills or limit their original concepts in order to create both a parametric solid model and a physical prototype.

Student experiences with the course have been tracked since 1999 using a survey, ${ }^{15}$ which may track student confidence more than competence. Forty-eight surveys were collected following the introduction of the Ekranoplan project. Roughly one third of the students wrote that the Ekranoplan project was the best part of the class. Answers to twelve of fourteen questions used in past surveys showed improvements. Student's enthusiasm for the project is also indicated by the quality of the models that they produced. During the last term, Fall 2003, two student teams created vehicles powered by electric motors. Two teams set and met goals to reach distance records set by the master's candidates. Upper class students have expressed regret about not being exposed to this project. One student has imported a parametric airfoil creation tool into both CATIA V5 and Pro-Engineer. Another student is constructing a larger, radio-controlled Ekranoplan to help characterize flight performance of ground effect flight.

\section{Conclusion}

The Ekranoplan project offers technology educators a unique design project to provide to their students. The project can be tailored to specific learning objectives targeted by standardized assessments. Students enjoy researching this novel vehicle technology. Participants indicate that they possess a better understanding of the design process. Students in Engineering Design Graphics I demonstrated additional computer modeling skills with multiple-part, parametric

"Proceedings of the 2004 American Society for Engineering Education Annual Conference \& Exposition Copyright $(2004$, American Society for Engineering Education” 
product assemblies. The project provides students with direct feedback on their design decisions. The author and colleague will continue to develop the techniques and lesson plans provided by the master's candidates to improve the Engineering Design Graphics I course at Western Washington University.

\section{Bibliography}

\footnotetext{
${ }^{1}$ H.C. "Skip" Smith, The Illustrated Guide to Aerodynamics, (New York: Tab Books, a division of McGraw-Hill, 1992), 80-83.

${ }^{2}$ Bill Gunston, The Encyclopedia of Russian Aircraft 1875 - 1995, (Osceola: Motorbooks International, 1995), 511521.

${ }^{3}$ Diane Beaudoin and David Ollis, “A Product and Process Engineering Laboratory for Freshmen,” Journal of Engineering Education 84, no. 3 (July 1995): 279-284.

${ }^{4}$ History Undercover: Soviet Top Secret Weapons VHS, 50 min., 2002, distributed by History Channel.

${ }^{5}$ H.C. "Skip" Smith, The Illustrated Guide to Aerodynamics, 45.

${ }^{6}$ Ira Abbott and Albert Von Doenhoff, Theory of Wing Sections, (New York: Dover Publications, 1959), 573.

${ }^{7}$ H.C. "Skip" Smith, The Illustrated Guide to Aerodynamics, 81-82.

${ }^{8}$ Ira Abbott and Albert Von Doenhoff, Theory of Wing Sections, 406-447.

${ }^{9}$ International Technology Education Association, Technology for All Americans Project, Standards for Technological Literacy (Reston: International Technology Education Association, 2000), 15.

${ }^{10}$ Jason Vander Hoek, "Ekranoplan W.I.G. Proposal" [Power Mechanics Curriculum Proposal], August 2002, Engineering Technology Department, Western Washington University, Bellingham.

${ }^{11}$ Mike Criner, "Wing in Ground Effect Proposal" [Power Mechanics Curriculum Proposal], August 2002, Engineering Technology Department, Western Washington University, Bellingham.

${ }^{12}$ Derek Bower, "Course Proposal", [Power Mechanics Curriculum Proposal], August 2002, Engineering Technology Department, Western Washington University, Bellingham.

${ }^{13}$ Jamie Harrington, "Power Mechanics" [Power Mechanics Curriculum Proposal], August 2002, Engineering Technology Department, Western Washington University, Bellingham.

${ }^{14}$ Sandra Shaw Courter, Susan Millar, and Lymon Lyons, "From the Students' Point of View: Experiences in a Freshman Engineering Design Course," Journal of Engineering Education 87, no. 3 (July 1998): 283-287.

${ }^{15}$ Jeffrey Newcomer, Eric McKell, Robert Raudebaugh, and David Kelly, "Creating a Strong Foundation with Engineering Design Graphics”, The Engineering Design Graphics Journal 65, no. 2 (Spring 1999): 30-42.
}

\section{Biographical Information}

\section{ERIC LEONHARDT}

Eric Leonhardt teaches courses in the Vehicle Research Institute and in the Manufacturing Engineering Technology program at Western Washington University. Prior to April, 2002, he worked for DaimlerChrysler in the CAx Research and Development Group. He teaches courses in Manufacturing Economics, Statics, Strengths, Power Mechanics and Vehicle Design. 